\title{
Competência de Juízo Moral entre Estudantes de Odontologia
}

\author{
Competence of Moral Judgment among \\ Dentistry Students
}

\author{
Tiago Policarpo Landim \\ Michael Sullivan Ferreira da Silva \\ Helvecio Neves Feitosa ${ }^{\text {II }}$ \\ Sharmênia de Araújo Soares Nuto III
}

\section{PALAVRAS-CHAVE}

- Ensino;

- Ética Odontológica;

- Desenvolvimento Moral;

- Odontologia.

\section{KEYWORDS}

- Teaching;

- Dental Ethics;

- Moral Development;

- Dentistry.

Recebido em: 22/06/2014

Aprovado em: 05/10/2014

REVISTA BRASILEIRA DE EDUCAÇ̄̃o MÉDICA

$4139(1): 41-4 ; 2015$
${ }^{I}$ Universidade de Fortaleza, Fortaleza, CE, Brasil.

"Iniversidade Federal do Ceará;Universidade de Fortaleza, Fortaleza, CE, Brasil.

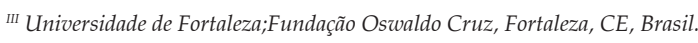

\begin{abstract}
RESUMO
Esta pesquisa objetivou avaliar a competência moral de estudantes de Odontologia no Estado do Ceará. O estudo foi do tipo observacional transversal descritivo. Aplicou-se o Moral Judgement Test (MJT) com os alunos regularmente matriculados no primeiro e último semestres dos cursos de Odontologia do Estado. Para a análise do ambiente de aprendizagem, realizou-se a coleta dos conteúdos das disciplinas e estágios de todas as IES envolvidas para consolidação das cargas horárias. Avaliou-se como variável dependente o aspecto cognitivo - competência de juízo moral calculada a partir do MJT e expressa pelo escore C. As variáveis independentes foram: (a) tipo de instituição; (b) tempo de aprendizagem; (c) gênero; (d) idade. Para análise da diferença estatística significante entre gênero, semestre e tipo de instituição, calculou-se a diferença de médias através do teste t.O teste de Anova foi utilizado para análise das diferenças entre grupos etários por semestre. Os resultados apontam que a média de competência de juízo moral (escore C)dos entrevistados foi de 18,3, não havendo diferença significativa entre os sexos. Analisando-se a média de escore $C$ dos estudantes do primeiro e último semestre, observou-se uma tendência de perda de competência do primeiro $(19,0)$ para o último semestre $(17,6)$ e uma diferença significativa entre alunos de instituições públicas $(21,0)$ e privadas $(16,5)$. Observou-se também que as disciplinas com conteúdo de Ciências Humanas não ultrapassaram $20 \%$ dos projetos pedagógicos dos cursos, condicionando os futuros cirurgiōes-dentistas a desenvolver uma competência moral limitada.
\end{abstract}

\begin{abstract}
This research aimed at assessing the moral competence of dental students in the state of Ceará. This was a cross-sectional, observational and descriptive study. We applied the Moral Judgment Test (MJT) with students enrolled in the first and last semesters of state dental courses and for the analysis of the learning environment, we collected the contents of the disciplines and internships of all Institutions involved for a consolidated account of study hours. As the dependent variable we assessed the cognitive aspect - moral judgment competence evaluated by MJT and expressed by $C$ score. As independent variables: a) type of institution; b) learning time; c) gender; d) age. For the assessment of statistical significance between gender, semester and type of institution, we calculated the difference of means, by the t test. The ANOVA test was used to assess the differences between age groups per semester. The results show that the average moral judgment competence (C score) of respondents was 18.3, with no significant difference between genders. Analyzing the average competence of students in the first and last semesters per institution resulted in a trend of loss of competence from the first (19.0) to the last semester (17.6) and a significant difference between students from public institutions (21.0) and private ones (16.5). It was also observed that the disciplines with human sciences content did not exceed $20 \%$ of the pedagogical projects, conditioning future dentists to develop limited moral competence.
\end{abstract}




\section{INTRODUÇÃO}

Na Conferência Mundial sobre Educação Superior, em 1998, convocada pela Organização das Nações Unidas para Educação, Ciência e Cultura (Unesco), foram propostas diretrizes claras sobre os docentes da educação superior,segundo as quais estes deveriam ensinar seus alunos a tomar iniciativas e a não ser unicamente detentores do saber. A formação e a investigação na universidade têm que contemplar problemas éticos de cada profissão, além de formar um especialista nesta matéria. O conhecimento deontológico deveria incrementar aprendizagens que permitissem o desenvolvimento ético e moral do cidadão, tanto na dimensão individual quanto na social $^{1}$.

A formação de cirurgiões-dentistas com embasamento generalista, humanista, crítico e reflexivo deve enfatizar a promoção da saúde e a prevenção de doenças, de modo que este profissional não vise somente à qualidade dentária. Para isto, deve-se priorizar um projeto pedagógico voltado aos problemas advindos das interações que se estabelecem entre Instituições de Ensino Superior (IES), governos e sociedade ${ }^{2}$.

Uma construção moral e ética será deficiente e terá valores invertidos se priorizar leis e regras, pois seria mecanicista e tecnicista, causando prejuízo à vida e aos direitos humanos. No contexto do ensino da Odontologia, as disciplinas de pura prática, realizadas nas clínicas da universidade, não contemplam a formação ética e moral. Em estudo realizado por Freitas et al. ${ }^{3}$, concluiu-se que o desenvolvimento do nível moral encontrado em formandos é baixo, sendo inadequado para a profissão e interferindo em valores éticos do cotidiano.

A formação do cirurgião-dentista não consegue desenvolver uma competência moral desejável, fato que acarretará consequências danosas ao futuro profissional, pacientes e sociedade. Deve-se ressaltar que a conduta profissional do universitário se inicia nos espaços de aprendizagem, e neste contexto as clínicas são espaços privilegiados para o desenvolvimento de condutas, funcionando como um campo para reflexão técnica e ética acerca de suas escolhas e procedimentos ${ }^{4}$.

O Brasil recebeu influência da Odontologia norte-americana, que se desenvolveu com base no Relatório Flexner, elaborado nos Estados Unidos em 1910 e que incorporou em seus pressupostos o caráter técnico-científico ${ }^{5}$.

Alguns autores criticaram a prática odontológica em que o ensino superior se caracterizava pelo excesso de tecnicismo em detrimento de aspectos fundamentais, como prevenção, uma relação paciente-profissional mais humanizada e a própria ética do cotidiano ${ }^{6-9}$. Esse modelo vem sendo bastante discutido, principalmente em razão de fraca resposta às ne- cessidades da população brasileira, elitização, individualização, altos custos, baixo impacto social e distanciamento entre a realidade epidemiológica e social da população ${ }^{5}$.

Apesar dessas críticas, as escolas de Odontologia do Brasil continuam formando profissionais voltados para o biologicismo, com técnicas e instrumentos sofisticados, excluindo os determinantes sociais e econômicos do processo saúde-doença, ou seja, formando profissionais sem uma visão integral do indivíduo. A abordagem social dos problemas relacionados à saúde não causa entusiasmo, nem tem muito prestígio entre estudantes e professores, sendo desenvolvidos conteúdos mais ligados às clínicas odontológicas ${ }^{5}$.

Diante de tal problemática, em 1998 houve a promulgação da nova Lei de Diretrizes e Bases da Educação (LDB). A norma estabelece que o perfil desejado é o de um profissional "tecnicamente capaz e socialmente sensível"3. Em 2002, o Ministério da Educação promulgou as Diretrizes Curriculares Nacionais (DCN) dos Cursos de Graduação em Odontologia, que direcionam a formação do cirurgião-dentista para um perfil generalista, humanista, crítico e reflexivo, para atuar em todos os níveis de atenção à saúde, com base no rigor técnico e científico, capacitado ao exercício de atividades referentes à saúde bucal da população, pautado em princípios éticos, legais e na transformação da realidade em beneficio da sociedade ${ }^{10}$.

Para o desenvolvimento de competências e habilidades gerais, o Artigo $4^{\circ}$ das $\mathrm{DCN}^{10}$ estabelece:

$$
\begin{aligned}
& \text { Os profissionais devem realizar seus serviços dentro dos mais } \\
& \text { altos padrões de qualidade e dos princípios da ética/bioética, } \\
& \text { tendo em conta que a responsabilidade da atenção à saúde } \\
& \text { não se encerra com o ato técnico, mas, sim, com a resolução } \\
& \text { do problema de saúde, tanto em nível individual quanto co- } \\
& \text { letivo (p.1). }
\end{aligned}
$$

A formação do cirurgião-dentista tem por objetivo dotar o profissional dos conhecimentos requeridos para o exercício moral e ético das seguintes competências e habilidades específicas: I - Respeitar os princípios éticos inerentes ao exercício profissional; V - Exercer sua profissão de forma articulada ao contexto social, entendendo-a como uma forma de participação e contribuição social; XX - Manter reconhecido padrão de ética profissional e conduta, e aplicá-lo em todos os aspectos da vida profissional ${ }^{10}$.

O papel do ensino superior como fomentador do desenvolvimento da competência de juízo moral tem sido questionado. Na prática, diversas pesquisas têm demonstrado que ocorre exatamente o contrário, ou seja, em muitas circunstân- 
cias, há uma regressão do processo de desenvolvimento do juízo moral. Este fenômeno remonta à década de 1960, quando Lawrence Kohlberg detectou em suas pesquisas que os estudantes de ensino superior apresentavam essa diminuição. $\mathrm{O}$ autor supôs, entretanto, que tal achado se devia a questões metodológicas. Estudos posteriores, contudo, corroboraram os achados iniciais de Kohlberg ${ }^{11-14}$. Lind ${ }^{12}$ atribuiu tal fato ao ambiente de ensino voltado para atender ao rápido desenvolvimento tecnológico.

O desenvolvimento moral é tópico de grande interesse para várias áreas do conhecimento humano, especialmente para a Psicologia, Filosofia, Sociologia e Educação. Como é que o ser humano, que nasce sem princípios morais, vai se transformando numa pessoa que respeita os outros e vive em sociedade? Esta tem sido uma questão importante, estudada muitas vezes sob o rótulo de socialização ${ }^{15}$. Outra questão pertinente é como incrementar tal desenvolvimento, com ênfase na escola ou na universidade.

A essência da moralidade, na visão de Kohlberg ${ }^{16}$, é o princípio da justiça, definida como uma distribuição de direitos e deveres regulados por conceitos de igualdade e reciprocidade. Os valores universais básicos são originários do interior dos indivíduos, na medida em que estes processam sua experiência social. Os ambientes produzem crenças específicas diferentes, que se apresentam numa progressão em direção à maturidade moral, de forma a manter os mesmos passos, em que as diferenças em valores básicos resultam em níveis diferentes de maturidade de pensamento sobre conceitos e aspectos sociais e morais básicos.

Os problemas da ética médica e das demais profissões da área da saúde e a moralidade dos nossos estudantes têm sido motivo de estudos em nosso país ${ }^{17-22}$. Cada um de nós entende o que a palavra "moralidade" significa, mas encontramos maior dificuldade em defini-la ou em praticá-la ${ }^{12}$. Entretanto, a partir dos estudos de Kohlberg ${ }^{16}$ e outros, a moralidade pode ser medida, e alguns testes estão disponíveis para isso. Tais testes avaliam a competência moral ou atitudes morais. A competência de juízo moral ou maturidade moral "é a capacidade de tomar decisões e julgamentos que são morais (isto é, baseados em princípios internos) com base em princípios internos e de agir de acordo com tais julgamentos" (p.425) ${ }^{23}$. Atitudes morais refletem a avaliação subjetiva e emocional dos problemas morais.

Assim, esta pesquisa busca avaliar a competência de juízo moral de estudantes de Odontologia no Ceará, propiciando a avaliação e a discussão acerca da formação ética e moral dos acadêmicos nas IES do Estado.

\section{METODOLOGIA}

O estudo foi do tipo observacional, transversal e descritivo, com abordagem quantitativa, sendo conduzido com base no território dos acadêmicos de Odontologia do Estado do Ceará no primeiro semestre de 2013.

A população do estudo foi constituída de 140 acadêmicos do primeiro semestre e 140 do último semestre do curso de Odontologia regularmente matriculados em cada IES pesquisada. O critério de inclusão foi estar regularmente matriculado no primeiro ou último semestre do curso de Odontologia das IES pesquisadas. Como critérios de exclusão, ter concluído outro curso de nível superior, ter preenchido o formulário parcial de modo que não possibilitasse a coleta total das informações ou a IES ainda não ter uma turma de concludentes.

Utilizou-se o Moral Judgement Test (MJT), última versão do instrumento validada para a língua portuguesa, para avaliar a competência de juízo moral, por permitir resultado quantitativo, livre de avaliação subjetiva ${ }^{24}$.

O MJT consiste em um questionário que contém dilemas morais, que confrontam o indivíduo com princípios morais e seus argumentos pró e contra, devendo o respondente exercer capacidade de julgamento com relação a todos os argumentos. De acordo com Lind ${ }^{11}$, os argumentos a favor indicam o nível de raciocínio moral para solucionar o dilema; quanto à reação aos argumentos contra, demonstra-se a habilidade em utilizar constantemente os princípios morais para julgar a conduta de outras pessoas.

O MJT consta de dois dilemas - do operário e do médico -, sendo que cada dilema possui 12 argumentos, distribuídos em seis argumentos a favor e seis contra, elaborados conforme o raciocínio dos estágios morais de Kohlberg ${ }^{16}$. Os seis argumentos a favor encontram-se organizados em termos dos raciocínios dos estágios de 1 a 6, assim como os argumentos contra. As escalas que avaliam o nível de concordância ou rejeição dos argumentos vão de menos (-) 4 a mais (+) $4^{25}$.

Com a aplicação do $M J T$ avalia-se a competência de juízo moral (escore C, C-index ou C-score), que demonstra a habilidade de julgar de acordo com a qualidade moral, mais do que segundo acordos de opinião ou outros fatores. $\mathrm{O}$ escore $C$ varia de 1 a 100 e indica a percentagem da variação do total de respostas de um indivíduo devido aos valores e conceitos das pessoas para a qualidade moral dos argumentos dados ou comportamentos. A média de competência de juízo moral recebeu a seguinte estratificação: baixo, 1 a 9; médio, 10 a 29; alto, 30 a 49; muito alto, acima de $50^{25}$ 
Neste estudo, avaliou-se como variável dependente o aspecto cognitivo-competência de juízo moral calculada a partir do MJT e expressa pelo escore C, como proposto pela teoria do duplo-aspecto de Lind ${ }^{11}$. E como variáveis independentes: (a) tipo de instituição - instituições competitivas são aquelas em que há mais de dez candidatos (estudantes) por vaga para admissão; e instituições não competitivas- são as que apresentam procura menor ${ }^{13,26}$ (neste estudo, as IES públicas são competitivas, e as privadas, não competitivas); (b) tempo de aprendizagem: aquisição de conhecimentos entre o primeiro e o último semestre; (c) gênero: avaliação comparativa do escore $C$ entre os alunos do sexo masculino e feminino; (d) idade: avaliação comparativa do escore $\mathrm{C}$, correlacionando-o com a idade (em anos completos) dos alunos. A idade foi consolidada em grupos etários.

Para a análise do ambiente de aprendizagem, realizou-se a coleta dos conteúdos das disciplinas e estágios de todas as IES envolvidas para consolidação das cargas horárias.

A aplicação do instrumento de coleta de dados deu-se após apresentação pessoal dos pesquisadores nas instituições envolvidas, seguida de uma breve exposição quanto aos objetivos da pesquisa, quando também foi realizada a entrega do Termo de Consentimento Livre e Esclarecido (TCLE) para leitura e assinatura. A aplicação desse instrumento realizou-se no primeiro mês de ingresso e no último semestre dos cursos de Odontologia das IES.

Foram analisados os projetos de ensino e projetos pedagógicos, com foco nos conteúdos e cargas horárias referentes à formação humanística.

Para a computação dos dados do MJT, utilizou-se uma matriz estatística denominada Manova-matriz de análise multivariada de variância-, que permite trabalhar com múltiplas variáveis dependentes. É uma variação dos testes Anova, que se apoiam na hipótese de que os grupos são semelhantes, e a variância em cada um (dentro) dos grupos é semelhante àquela entre os grupos. O que se faz é comparar a variabilidade das médias de todas as amostras com a variabilidade dentro das amostras. $\mathrm{O}$ modelo foi calculado no programa Excel. O banco de dados foi exportado para o programa Stata 12.0, em que se realizou a análise dos dados. Para análise da diferença estatística significante entre gênero, semestre e tipo de instituição, calculou-se a diferença de médias, através do teste $t$. O teste de Anova foi utilizado para análise das diferenças entre grupos etários por semestre. O nível de significância considerado foi de 5\% ou quando a diferença entre as médias dos escores foi maior que 5 pontos $^{25}$.
O projeto de pesquisa foi submetido ao Comitê de Ética em Pesquisa da Universidade de Fortaleza, sendo aprovado com o número 336.896/2013. Todos os participantes assinaram o TCLE, após informação detalhada sobre os objetivos da pesquisa, em obediência aos ditames da Resolução 196/96 do Conselho Nacional de Saúde, que normatiza os aspectos éticos e bioéticos em pesquisa com seres humanos. Respeitaram-se também as normas emanadas da Declaração de Helsinki, na sua última versão ${ }^{27}$. As instituições de ensino tiveram suas identidades mantidas em sigilo, sendo revelada somente sua natureza (pública ou privada).

O teste empregado nesta pesquisa não é válido para avaliar a competência de juízo moral do indivíduo isoladamente, mas para a investigação de grupos. Os indivíduos pesquisados não foram identificados por nome, iniciais ou qualquer outra característica, sendo apenas preenchidos alguns dados demográficos, como idade e sexo, além do semestre que cursavam, bem como se já tinham ou não nível superior em outra área do conhecimento. A participação na pesquisa foi espontânea, após as explicações sobre os objetivos e o instrumento que seria utilizado.

\section{RESULTADOS}

Na população estudada observa-se prevalência do sexo feminino (194-69,2\%) sobre o masculino (86-30,8\%). A média de competência de juízo moral (escore C) dos entrevistados foi de 18,3, não havendo diferença significativa entre os sexos $(\mathrm{p}=0,441)$, pois no sexo masculino foi de 18,5 e no feminino de 18,2 (Tabela 1)

\begin{tabular}{|c|c|c|c|c|c|c|c|}
\hline $\begin{array}{l}\text { Influ } \\
\text { global (e }\end{array}$ & $\begin{array}{r}\text { ència do gé } \\
\text { score } C) \text { e } \\
\text { de } O\end{array}$ & $\begin{array}{l}\text { ênero } 1 \\
\text { por di } \\
\text { dontol }\end{array}$ & $\begin{array}{l}\text { TABEL } \\
\text { na cor } \\
\text { lema } \\
\text { logia } 1\end{array}$ & $\begin{array}{l}1 \\
\text { petênc } \\
\text { entre e } \\
\text { Ceará }\end{array}$ & $\begin{array}{l}\text { a de ju } \\
\text { tudan } \\
2013\end{array}$ & $\begin{array}{l}\text { lízo mo } \\
\text { tes de }\end{array}$ & $\begin{array}{l}\text { ral } \\
\text { ursos }\end{array}$ \\
\hline & & & & mpetên & cia de $\mathbf{j}$ & uízo mo & \\
\hline Gênero & $\mathrm{N}(\%)$ & C-op & erário & C-m & dico & esco & re $\mathrm{C}$ \\
\hline & & média & $\mathrm{p}$ & média & p & média & p \\
\hline Mulheres & $194(69,2)$ & 38,1 & 0,418 & 23,7 & 0,452 & 18,2 & 0,441 \\
\hline Homens & $86(30,8)$ & 38,7 & & 24,0 & & 18,5 & \\
\hline Total & $280(100,0)$ & 38,3 & & 23,8 & & 18,3 & \\
\hline
\end{tabular}

No dilema do operário, obteve-se uma média de 38,7 para os homens e 38,1 para as mulheres $(p=0,418)$. No dilema médico, as médias foram menores, sendo 24,0 para os homens e 
23,7 para as mulheres ( $\mathrm{p}=0,452)$, observando-se o "fenômeno da segmentação" (Tabela 1).

Em relação ao grupo etário, 53 (37,9\%) alunos do primeiro semestre estavam entre 17-18 anos, 45 (32,1\%) entre 19-20 anos, e 42 (30,0\%) acima de 21 anos. Para os alunos do último semestre, 44 (31,4\%) estavam entre 20-21 anos, 59 (42,1\%) entre 23-24 anos, e 37 (26,5\%) acima de 25 anos (Tabela 2).

\section{TABELA 2}

Influência do grupo etário na competência de juízo moral global (escore C) e por dilemas entre estudantes do primeiro e último semestre de cursos de Odontologia no Ceará, 2013

\begin{tabular}{|c|c|c|c|c|c|c|c|}
\hline \multirow{2}{*}{$\begin{array}{l}\text { Semestre/ } \\
\text { idade }\end{array}$} & \multirow[b]{2}{*}{ N (\%) } & \multicolumn{6}{|c|}{ Competência de juízo moral } \\
\hline & & \multicolumn{2}{|c|}{ C-operário } & \multicolumn{2}{|c|}{ C-médico } & \multicolumn{2}{|c|}{ escore C } \\
\hline $\begin{array}{l}\text { Primeiro } \\
\text { semestre }\end{array}$ & & média & p & média & p & média & p \\
\hline \multicolumn{8}{|l|}{ Idade (anos) } \\
\hline $17-18$ & $53(37,9)$ & 41,5 & 0,244 & 24,5 & 0,998 & 19,0 & 0,371 \\
\hline $19-20$ & $45(32,1)$ & 45,3 & & 24,7 & & 21,1 & \\
\hline acima de 21 & $42(30,0)$ & 37,3 & & 24,7 & & 17,0 & \\
\hline Total & $140(100,0)$ & 41,4 & & 24,6 & & 19,0 & \\
\hline $\begin{array}{l}\text { Último } \\
\text { semestre }\end{array}$ & & média & $\mathrm{p}$ & média & $\mathrm{p}$ & média & p \\
\hline \multicolumn{8}{|l|}{ Idade (anos) } \\
\hline $20-22$ & $44(31,4)$ & 35,4 & 0,943 & 22,7 & 0,494 & 18,0 & 0,565 \\
\hline 23-24 & $59(42,1)$ & 34,5 & & 21,4 & & 16,4 & \\
\hline acima de 25 & $37(26,5)$ & 36,0 & & 26,2 & & 19,1 & \\
\hline Total & $140(100,0)$ & 35,3 & & 23,4 & & 17,89 & \\
\hline
\end{tabular}

Quando se relacionaram os resultados por grupo etário, verificou-se que o escore $C$ do primeiro semestre não seguiu um padrão, tendo aumentado do grupo etário de 19-20 anos $(21,1)$, mas depois diminuído nos alunos acima de 21 anos $(17,0)$, sem significância estatística $(p=0,371)$. Quanto ao desempenho por dilemas, o grupo etário de 19-20 anos apresentou o melhor desempenho no dilema do operário; no dilema médico, as três faixas etárias tiveram desempenho semelhante, sendo observado o fenômeno da "segmentação moral", em que o dilema do operário obteve melhor desempenho $(41,4)$ do que o médico $(24,6)$, mas sem significância estatística nos dois dilemas, porém com diferença superior a 5 pontos (Tabela 2).

Nos alunos do último semestre, também não foi seguido um padrão, pois o escore $C$ diminuiu nos alunos de 23-24 anos $(16,4)$, mas aumentou nos alunos acima de 25 anos $(19,1)$. Na análise de desempenho por dilemas, observa-se que os alunos da segunda faixa etária (23-24 anos) apresentaram os piores resultados, e os alunos acima de 25 anos os melhores, nos dois dilemas, não tendo havido significância estatística (C-escore $\mathrm{p}=0,565$; C-operário $\mathrm{p}=0,943$; $\mathrm{C}$-médico $\mathrm{p}=0,494$ ). Foi mantido o "fenômeno da segmentação" nas três faixas etárias, em que as melhores médias foram relacionadas ao dilema do operário, em detrimento do dilema médico (Tabela 2).

Quando se analisou o escore C dos estudantes do primeiro e do último semestre, observou-se uma tendência de regressão da competência do primeiro $(19,0)$ para o último semestre $(17,6)$, mas essa redução não foi significante estatisticamente $(\mathrm{p}=0,184)$ (Tabela 3).

\section{TABELA 3}

Influência do semestre na competência de juízo moral global (escore C) e por dilemas entre estudantes de cursos de Odontologia no Ceará, 2013

\begin{tabular}{cccccccc} 
& & \multicolumn{5}{c}{ Competência de juízo moral } \\
\cline { 3 - 8 } Semestre & N (\%) & \multicolumn{2}{c}{ C-operário } & C-médico & escore C \\
\cline { 3 - 8 } & & média & p & média & p & média & p \\
\hline Primeiro & $140(50,0)$ & 41,4 & 0,008 & 23,7 & 0,256 & 19,0 & 0,184 \\
Último & $140(50,0)$ & 35,2 & 24,0 & 17,6 \\
\hline Total & $\mathbf{2 8 0}(\mathbf{1 0 0 , 0 )}$ & $\mathbf{3 8 , 3}$ & $\mathbf{2 3 , 8}$ & $\mathbf{1 8 , 3}$ \\
\hline
\end{tabular}

No dilema do operário, a competência também diminuiu do primeiro $(41,4)$ para o último semestre $(35,2)$, havendo significância estatística na perda de competência moral do primeiro para o último semestre para a solução dos dilemas $(p=0,008)$. No dilema médico, houve um ligeiro acréscimo da competência moral do primeiro $(23,7)$ para o último $(24,0)$ semestre, mas considera-se semelhante, pois essa diferença não é tida como significante $(p=0,256)$ e foi inferior a 5 pontos(Tabela 3).

O escore $C$ dos estudantes por tipo de instituição, pública ou privada, indica uma superioridade da competência moral dos alunos das instituições públicas $(21,0)$ em detrimento das privadas $(16,5)$, apresentando significância estatística $(\mathrm{p}=0,002)$ (Tabela 4). 


\section{TABela 4}

Influência do tipo de instituição na competência de juízo moral global (escore $\mathrm{C}$ ) e por dilemas entre estudantes de Cursos de Odontologia no Ceará, 2013

\begin{tabular}{|c|c|c|c|c|c|c|c|}
\hline \multirow{3}{*}{$\begin{array}{c}\text { Tipo de } \\
\text { instituição }\end{array}$} & \multirow{3}{*}{ N (\%) } & \multicolumn{6}{|c|}{ Competência de juízo moral } \\
\hline & & \multicolumn{2}{|c|}{ C-operário } & \multicolumn{2}{|c|}{ C-médico } & \multicolumn{2}{|c|}{ escore C } \\
\hline & & média & $\mathrm{p}$ & média & $\mathrm{p}$ & média & $\mathrm{p}$ \\
\hline Privada & $163(58,21)$ & 36,7 & 0,073 & 23,1 & 0,229 & 16,5 & 0,002 \\
\hline Pública & $117(41,79)$ & 40,6 & & 24,9 & & 21,0 & \\
\hline Total & $280(100,0)$ & 38,3 & & 23,8 & & 18,3 & \\
\hline
\end{tabular}

Tanto no dilema do operário, quanto no do médico, as melhores médias foram das instituições públicas, respectivamente 40,6 ( $\mathrm{p}=0,073)$ e 24,9 ( $\mathrm{p}=0,229)$, mas sem significância estatística quando houve a separação por dilemas.Independentemente do tipo de instituição, permaneceu o "fenômeno da segmentação moral", em que as melhores médias estiveram relacionadas ao dilema do operário (Tabela 4).

Com base na análise dos projetos de ensino e projetos pedagógicos dos cursos de graduação estudados, assim como dos conteúdos e cargas horárias referentes à formação humana, observou-se que as disciplinas com o conteúdo de Humanas - importantes para o desenvolvimento da competência moral - não atingiram $20 \%$ dos projetos pedagógicos dos cursos, encontrando-se os índices mais altos nas instituições particulares (Tabela 5).

\section{TABELA 5}

Número e percentual de créditos nas disciplinas e estágios em Ciências Humanas e Sociais, e nas disciplinas e estágios clínicos básicos em cursos de Odontologia de quatro IES da cidade de Fortaleza (CE)

\begin{tabular}{lcccccc} 
& \multicolumn{1}{c}{$\begin{array}{c}\text { Créditos } \\
\text { em Ciências } \\
\text { Humanas e } \\
\text { Sociais }\end{array}$} & $\begin{array}{l}\text { Créditos em } \\
\text { disciplinas } \\
\text { e estágios } \\
\text { clínicos }\end{array}$ & \multicolumn{1}{c}{$\begin{array}{c}\text { Total de } \\
\text { créditos da } \\
\text { graduação }\end{array}$} \\
\hline P & $\%$ & n & $\%$ & n & $\%$ \\
\hline Pública A & 37 & 12,4 & 263 & 87,6 & 300 & 100,0 \\
Privadica B & 39 & 12,5 & 273 & 87,5 & 312 & 100,0 \\
Privada B & 36 & 18,8 & 156 & 81,2 & 192 & 100,0 \\
\hline
\end{tabular}

\section{DISCUSSÃO}

O MJT permite testar modernas teorias de desenvolvimento moral, educação e métodos educacionais quanto ao poder de elevar a competência moral dos sujeitos submetidos a eles ${ }^{28}$.

Neste estudo, a média geral de competência moral foi "média" $(18,3)$, fato verificado nos dois gêneros e em todos os grupos etários, tanto para os alunos ingressantes - que atingiram uma competência moral de 19,0 -, como para os alunos do último semestre $(C$-escore $=17,9)$. Uma realidade inferior à do nosso estudo foi encontrada em graduandos de Pedagogia na Faculdade de Filosofia e Ciência, Campus Marília, em que o grupo de alunos pesquisados desse curso obteve um C-escore "baixo" no primeiro ano, de 8,85, e no último ano, de 9,3029.

Em pesquisa realizada com estudantes de Medicina ${ }^{25}$, a realidade encontrada foi superior à do nosso estudo: média de competência geral 23,4, classificada como "média", para os dois gêneros. E em alguns grupos etários, como de 17-18 anos nos ingressantes, o C-escore atingiu 30,1, sendo classificado como "alto". Na comparação entre estudantes de Odontologia e Medicina, os estudantes de Medicina apresentam um C-escore maior do que os de Odontologia desse estudo.

Assim como neste estudo com estudantes de Odontologia, em que não houve diferença estatística significante entre gênero e grupos etários, uma pesquisa comparativa de estudantes de Medicina do Brasil e Portugal ${ }^{30}$ também não apresentou diferença significativa entre gêneros e grupos etários.

$\mathrm{Na}$ estratificação por dilemas em nosso estudo, observamos maior média no dilema do C-operário em relação ao C-médico: 38,3 e 23,8, respectivamente, com um índice expressivo dos alunos do primeiro semestre $(41,4)$ no dilema operário sobre o dilema médico $(23,7)$ para alunos do mesmo semestre. O fenômeno da segmentação moral também foi identificado em outro estudo ${ }^{25}$, em que alunos de Medicina têm maiores índices para o dilema do operário sobre dilema médico - 43,2 e 31,0, respectivamente.

Em estudo que compara alunos de Medicina no Brasil e em Portugal ${ }^{30}$, houve diminuição dos valores dos dilemas do operário e do médico nos dois países, mas a diferença maior foi encontrada no Brasil. Essa realidade foi confirmada em outros estudos em que alunos na América Latina têm competência moral mais baixa do que estudantes americanos e europeus $^{12,13,20,28,31}$.

Bataglia ${ }^{32}$, para esclarecer a queda de competência moral e relacioná-la à pior performance para o dilema médico, realizou uma segmentação da avaliação por dilemas, que resultou nos índices mais baixos no dilema do médico do que do trabalhador.Nesse estudo, também se observa queda do C-escore 
dos estudantes do primeiro para o último semestre, embora não significante,o que caracteriza uma estagnação da competência moral.

Outros pesquisadores ${ }^{12,25,30}$ obtiveram a mesma linha de resultado, em que o aluno entra com certo nível de competência moral,que decai no decorrer do curso. O que diferencia alunos brasileiros é que estes já entram com baixo nível de competência moral, e com isso a média do C-escore fica ainda menor.

Essa mesma característica aparece em nosso estudo, em que o desempenho para o dilema do operário é superior ao do médico. Na análise de tipo de instituição - pública e privada -, com índices de 38,3 para o dilema do operário e de 23,8 para o dilema médico,observamos que as instituições públicas sobressaíram em relação às instituições privadas. Embora estas apresentem ligeiro aumento de disciplinas ou estágios com ênfase em Ciências Humanas e Sociais, esse incremento não acarreta aumento no C-escore, o que mostra que as estratégias de ensino-aprendizagem adotadas não promovem o desenvolvimento da competência moral.

Em nosso estudo, assim como nos demais que estão sendo comparados nesta discussão, não consideramos outras variantes que podem influenciar o C-escore, como a região de origem dos alunos (urbana ou rural), a formação religiosa e outros aspectos culturais que podem influir sobre a competência moral.

Tudo isso nos leva a supor que a capacidade de tomar decisões e fazer julgamentos de natureza moral, ou seja, com base em princípios internos, e agir de acordo com esses julgamentos está relacionada, principalmente, com a formação familiar e escolar, ou seja, tudo aquilo que o aluno viveu antes de ingressar na faculdade ${ }^{29}$.

Os dados encontrados nesta pesquisa corroboram a hipótese de $\operatorname{Lind}^{33}$ de que, além de não ser invariavelmente crescente, a construção da competência de juízo moral falha se os processos educacionais pararem ou não fomentarem o desenvolvimento do raciocínio e da competência moral antes de o adolescente ter alcançado um nível suficientemente alto, ou seja, autossustentável, que pode, inclusive, retroceder em relação ao desenvolvimento moral antes alcançado. Estes dados evidenciam a importância da educação no processo de desenvolvimento da competência moral dos adolescentes, sendo importante contribuirmos para criar modelos de escolas com uma qualidade educacional capaz de educar e desenvolver os aspectos tanto cognitivos quanto morais dos alunos, adotando estratégias adequadas a tal finalidade.

O emprego de metodologias adequadas de discussão de dilemas morais constitui uma alternativa promissora para o desenvolvimento moral de pré-adolescentes, adolescentes e adultos jovens ${ }^{34,35}$.Uma das técnicas é a discussão de dilemas proposta por Blatt e Kohlberg, que consiste em formar um grupo de 10 a 12 pessoas de diferentes estágios de desenvolvimento moral para discutir dilemas, geralmente sob a orientação de um professor, psicólogo ou orientador educacional que coordena a discussão, chamando a atenção para argumentos típicos de estágios superiores, propostos por elementos do grupo ou pelo próprio coordenador. Várias sessões dessa técnica têm tido sucesso em promover a maturação de um estágio para outro. Programas de educação moral em vários ambientes escolares têm utilizado essa técnica ${ }^{36,37}$, inclusive no Brasil $^{38,39}$. Outro modelo é o KMDD (Konstanz Method of Dilemma Discussion), proposto por Lind ${ }^{40}$, que tem gerado resultados positivos no desenvolvimento da competência moral.

\section{CONCLUSÃO}

Na educação odontológica no estudo realizado, observa-se o desenvolvimento de conteúdos mais ligados aos ambulatórios da escola, ou seja, referentes às clínicas odontológicas, apresentando uma inexpressiva inclusão de disciplinas e estágios que englobem aspectos ligados às Ciências Humanas e Sociais.

Assim, é baixo o nível de competência de juízo moral encontrado entre os estudantes dos cursos de Odontologia pesquisados. Devemos repensar as estratégias de ensino-aprendizagem no sentido de fomentar o desenvolvimento da competência moral dos estudantes, preparando-os melhor para o enfrentamento dos dilemas éticos no dia a dia do exercício profissional, o que resultará em benefícios não apenas para os futuros profissionais, mas, sobretudo, para os pacientes e a sociedade.

\section{AGRADECIMENTOS}

Agradecemos ao Conselho Nacional de Desenvolvimento Científico e Tecnológico (CNPq) e à Fundação Edson Queiroz pelo financiamento da pesquisa através dos programas de Iniciação Científica PIBIC/CNPq e PAVIC/FEQ.

\section{REFERÊNCIAS}

1. Schuh CM, Albuquerque IM. A ética na formação dos profissionais da saúde: algumas reflexões. Rev Bioét 2009;17(1):55-60.

2. Lazzarin HC, Nakama L, Cordoni Junior L. Percepção de professores de Odontologia no processo de ensino-aprendizagem. Ciênc saúde coletiva 2010; 15(1): 1801-1810.

3. Freitas SFT, Kovaleski DF, Boing AF. Desenvolvimento moral em formando de um curso de Odontologia: uma avaliação construtivista. Ciênc saúde coletiva 2005; 10(2):453-462. 
4. Ribeiro EG, Machado MIV. Os problemas éticos no atendimento a pacientes na clínica odontológica de ensino. Ciênc saúde coletiva 2007; 12(3): 755-764.

5. Carvalho RB, Costa TBC, Gomes MJ, Santos KT, Guerra SMG. Formação docente em Odontologia no Brasil: sugestões de mudanças após as diretrizes curriculares nacionais. Rev bras pesq saúde 2010; 12(4):39-44.

6. Mendes EV, Marcos B. Odontologia integral: bases teóricas e suas implicações no ensino e na pesquisa odontológica. Belo Horizonte: FUMARC - PUC/MG; 1985.

7. Cordón JAP. Consideraciones sobre "simplificación" en odontología. Rev CERÓN1977; 2(1):8-9.

8. Cordón JAP. Prevención y racionalización en estomatología. Rev. CERÓN 1982; (2):2-3.

9. Cordón JAP, Silva HO. Las categorías "monopolio" y “desmonopolización" en estomatología. Acta Odón Venezolana1980; 18(3):419-38.

10. Brasil. Ministério da Educação. Diretrizes nacionais do curso de graduação em Odontologia. Resolução CNE/CES n03 de 19 de fevereiro de 2002. Diário Oficial da União. Brasília, 4 mar. 2002; Seção 1, p. 10.

11. Lind G,Hartmann HA, Wakenhut R. Moral development and the social environment. Studies in psychology and philosophy of moral judgment and education. Chicago: Precedent Publishing Inc., 1985.

12. Lind G. Moral regression in medical students and their learning environment. Rev Bras Educ Med 2000; 24(3):24-33.

13. Schillinger M. Learning environment and moral development: How university education fosters moral judgment competence in Brazil and two German-speaking countries. Aachen: Shaker Verlag; 2006.

14. Slováckova B, Slovacek L. Moral Judgment Competence and moral attitudes of Medical Students. Nurs Ethics 2007;14(3):320-8.

15. Biaggio AMB.Lawrence Kohlberg: ética e educação moral. 2.ed. São Paulo: Moderna, 2006.

16. Kohlberg L. From is to ought: How to commit the naturalistic fallacy and get away with the study of moral development. In: Mischel TS. Cognitive Development and Epistemology. New York: Academic Press; 1971.

17. Biaggio AMB. Uma comparação transcultural de estudantes universitários brasileiros e norte-americanos na medida de julgamento moral de Kohlberg. Arq Bras Psicol Aplic 1975; 27(2):71-81.

18. Biaggio AMB. A developmental study of moral judgment of Brazilian subjects. Interamerican. J Psycol 1976;10(2):71-8.

19. Biaggio AMB, BarretoMSL. Adaptação de uma medida objetiva de julgamento moral. Arq Bras Psicol 1991; 43(1/2): 107-119.
20. Bataglia P. A construção da competência moral na formação do psicólogo. São Paulo; 2001. Tese [Doutorado] - Instituto de Psicologia da Universidade de São Paulo.

21. Oliveira MS. Desenvolvimento da competência de juízo moral e ambiente de ensino: uma investigação com estudantes de graduação em enfermagem. Rio de Janeiro; 2008. Mestrado [Dissertação] - Escola Nacional de Saúde Pública Sérgio Arouca.

22. Von Rondon M. A construção da competência moral e a influência da religião: contribuições para a bioética. Rio de Janeiro; 2009. Mestrado [Dissertação] - Escola Nacional de Saúde Pública Sérgio Arouca.

23. Kohlberg L. Development of moral caracter and moral ideology. In: Hoffman ML, Hoffman LW. Review of child development research. New York: Russel Sage Fundation; 1964. p.363-431.

24. Lind G,Schillinger M, Bataglia P. The Moral Judgment Test. 2005.Disponível em: <Http://www.uni-konstanz.de/ag-moral/> [Acesso em: 29 mai. 2013].

25. Feitosa HN, Rego S, Bataglia P, Rego G, Nunes R. Competência de juízo moral dos estudantes de Medicina: um estudo piloto. Rev Bras Educ Med 2013;37(1):5-14.

26. Schwartman S. Equity, Quality and Relevance in Higher Education in Brazil. An Acad Bras Ciênc. 2004;26:173-88.

27. World Medical Association Declaration of Helsink. Ethical Principles for Medical Research Involving $\mathrm{Hu}-$ man Subjects. 59th WMA General Assembly, Seoul, October 2008. Disponível em:<http://www.wma.net/ en/30publications/10policies/b3/index.html $>$ [Acesso em: 29 mai. 2013].

28. Bataglia PUR, Morais A, Lepre RM. A teoria de Kohlberg sobre o desenvolvimento do raciocínio moral e os instrumentos de avaliação de juízo e competência moral em uso no Brasil. Estudos de Psicologia2010; 15(1): 25-32.

29. Deolindo KLS, Bataglia PUR. Desenvolvimento da competência Moral em Graduandos de Pedagogia. 2009. Disponível em: <http://prope.unesp.br/xxiii_cic/ver_resumo.php? area $=100064 \&$ subarea $=18909 \&$ congresso $=32 \& C$ $\mathrm{PF}=40727702807>$ Acesso em: 29 mai. 2013.

30. Feitosa HN, Rego S, Bataglia PUR, Sancho KFCB, Rego G, Nunes R. Moral judgment competence of medical students: a transcultural study. Adv in Heath Sci Educ. 2013; 18(5):1067-1085.

31. Moreno C. Moral education in higher education and the transformation of a concern: a historical account. $31^{\circ}$ Annual Meetingor the Association for Moral Education. Cambridge: Massachussets; 2005. 
32. Bataglia PUR. A validação do Teste de Juízo Moral (MJT) para diferentes culturas: o caso brasileiro. Psicol. reflex crit 2010; 23(1):83-91.

33. Lind G. Educational environments which promote self-sustained moral development. New York: American Educational Research Association;1996.

34. Blatt M, Kohlberg L. The effects of classroom moral discussion upon children's level of moral judgment. Journal of Moral Education 1975; 4:129-161.

35. Power FC, Higgins A, Kohlberg L. Kohlberg's Approach to Moral Education.Massachussets: Harvard University Press;1989.

36. Gibbs J, Arnold KD, Ahlborn H, Chessman F. Facilitation of Sociomoral Reasoning in Delinquents. Journal of Consulting and Clinical Psychology 1984; 52:37-45.

37. Berkowitz M. The role of discussion in moral education. En M. Oser \& F. Oser (Eds.). Moral Education: Theory and Application. New Jersey: Erlbaum; 1985. p. 197-218.

38. Rodrigues ADB. O desenvolvimento do julgamento moral em situação de sala de aula - em estudo quase-experimental. Porto Alegre; 1976. Mestrado [Dissertação] - Pontifícia Universidade Católica do Rio Grande do Sul.

39. Biaggio AMB. Discussões de julgamento moral.Psicologia: Teoria e Pesquisa 1985; 1: 195-204.

40. Lerkiabundit S, Utaipan P, Laohawiriyanon C, Teo A. Randomized controlled study of the impact of the Konstanz method of dilemma discussion on moral judgment. J Allied Health. 2006; 35:101-8.

\section{CONTRIBUIÇÃO DOS AUTORES}

Tiago Policarpo Landim e Michael Sullivan Ferreira da Silva foram responsáveis pela coleta de dados, elaboração e revisão do artigo. Helvecio Neves Feitosa e Sharmênia de Araújo Soares Nuto foram responsáveis pela concepção do projeto, desenho do estudo, coleta de dados, elaboração e revisão do artigo.

\section{CONFLITO DE INTERESSES}

Declarou não haver.

\section{ENDEREÇO PARA CORRESPONDÊNCIA}

Tiago Policarpo Landim

Rua Matos Vasconcelos 1548

Bairro Damas - Fortaleza

CEP 60426-110 - CE

E-mail: tiago.policarpo@hotmail.com

Sharmênia de Araújo Soares Nuto

Rua Olegário Memória 4275 - casa 26

Bairro: Sapiranga- Fortaleza

CEP 60833-045 - CE

E-mail: nuto@unifor.br 